\title{
Detection of Cryptosporidium oocysts in calves and children in Mosul, Iraq
}

\section{Tawfiq I. Al-alousi ${ }^{1}$ and Omaima I. Mahmood \\ 1- College of Veterinary Medicine/Tikrit Univercity \\ Summary}

This study was carried out during May-October 2010 to determine the prevalence of Cryptosporidium spp. in calves and children in rural areas around Mosul, north of Iraq. A total of 78 faecal samples were taken from calves which were no more than one year old. Information about age, consistency of faeces (as diarrheic or normal) and contact with human were recorded. At the same time, 95 stool samples were taken from children aged one month to 12 years old suffering from diarrhea and living in the same farms where the samples of calves have been collected. All samples were stained with modified Ziehl-Neelsen acid-fast stain and Auramine $\mathrm{O}$ techniques to detect the presence of Cryptosporidium oocysts. Results revealed that the prevalence of Cryptosporidium in calves and children were $43.56 \%$ and $18.9 \%$, respectively. Comparison of results obtained with the two stain techniques showed no significant difference and being sensitive.

\section{الكثف عن أكياس بيض طفيلي .Cryptosporidium sp في العجول والأطفال في مدينة الموصل , العراق$$
\text { توفيق إبراهيم الالوسي 1 و اميمة إبراهيم محمود }
$$

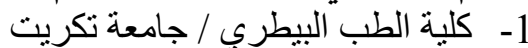 \\ الخلاصة}

أجريت هذه الدر اسة لتحديد نسبة انتشار طفيلي .Cryptosporidium sp في العجول و الأطفال في المناطق الريفية

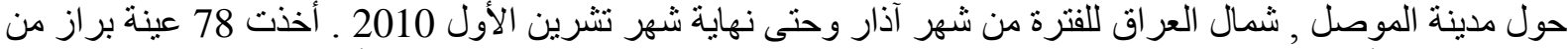

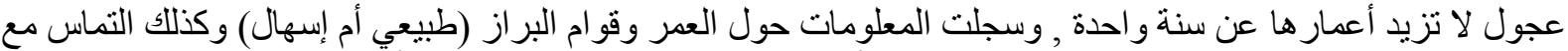

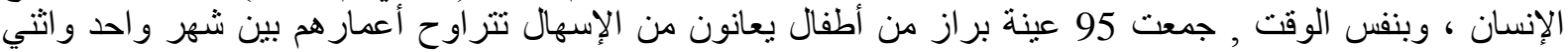

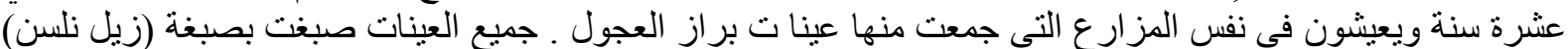

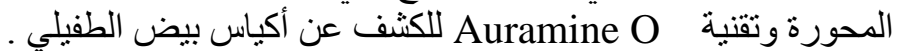

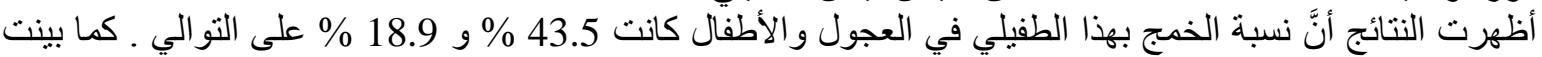
النتائج عدم وجود فرقا معنويا مهما بين طريقتي الصبغ ,إضافة إلى كفاءة وحساسية كلا الطريقتين المتبعتين للكثثف عن لكن أكياس بيض طفيلي .Cryptosporidium sp

\section{Introduction}

Members of the genus Cryptosporidium are eukaryotic organisms, including obligate and intracellular parasites. Cryptosporidium has a complex life cycle, including both sexual and asexual reproduction, an auto-infectious cycle, and the ability to complete its development within a single host (1). The transmission form is a robust, environmentally resistant oocyst, excreted in the stool, which can exist for long periods of time in the environment. Because animals, in particular domesticated livestock, are its primary host, human infection is usually zoonotic $(2,3)$. Those at greatest risk are immunocompromised adults and children, especially in patient with AIDS, children in day care, travelers to endemic regions, dairy or cattle farm workers or their families or contacts, household contacts of cases or carriers, and possibly owners of infected dogs or cats or their neighbors (4).

Cryptosporidium is related to direct zoonotic and this parasite infects human directly from animals (5). Cryptosporidium parvum is the major species seen in humans and animals. $C$. parvum type I (C.hominis) is found in humans, and C. parvum type II (C. bovis) is found in humans and animals (especially ruminants) (6). As well as causing morbidity and mortality in animals, cryptosporidiosis in lambs and calves is considered to be an infection source for 
humans (6). Infected calves can eliminate a large number of oocysts in their faeces and contaminate fresh food, drinking and recreational water causing infection affecting humans and other animals (7). The presence of Cryptosporidium spp. in faeces of calves and children has been reported in other countries in the world $(6,7,8,9,10)$ and studies on risk factors have also been carried out, usually focusing on management factors at the herd level, derived from questionnaire gathered from farmers (11). The major clinical sign in cryptosporidiosis is gastroenteritis that is self-limiting. But in persons who are immunocompromised, it may cause chronic diarrhea (12).

The present study was investigated to determine the prevalence of Cryptosporidium in calves and children in rural areas around Mosul city and also to understand its epidemiology by using two microscopic methods Ziehl-Neelsen acid-fast and Auramine O techniques.

\section{Materials and methods}

Since May to October 2010, samples were obtained from cattle farms in rural areas around Mosul ,Iraq. A total of (78) fresh stool samples were collected directly from diarrheic calves no more one year old, using sterile latex gloves. Information about age, consistency of faeces (as diarrheic or normal) and contact with human were collected and recorded. At the same time, a total of (95) stool samples were also taken from children aged one month to 12 years suffering from diarrhea and living in the same farms where the samples of calves have been collected. Each sample was collected in a dry and clean plastic container labeled with child's name, age, living location and stored at $4^{\circ} \mathrm{C}$ until they were processed.

The samples were submitted to sedimentation of oocysts by centrifugation, in which the sediment was fixed with methanol for 5 minutes and then used for the smearing procedure (13). The stool were smeared into glass slides and stained using the modified Ziehl Neelsen (14) and Auramine O techniques (15). The samples stained by the Ziehl Neelsen technique were examined under light microscopy $(100 \mathrm{X})$. The Auramine $\mathrm{O}$ stained smears were analyzed by fluorescence microscopy, after a previous screening (100 X) .

A sample was considered positive for cryptosporidiosis, if an oocyst was identified based on morphology including optical properties, internal structure, size, and shape. In the Auramine O method, samples were studied with dark field microscope and Cryptosporidium oocysts had fluorescent property.

Statistical analysis was performed using analysis of one-way ANOVA analysis with the help of SPSS computer software (16).

\section{Results}

The results of this study confirmed that cryptosporidial infection was present in calves in rural areas around Mosul. Out of (78) fecal samples examined (34) (43.56\%) samples were positive for Cryptosporidium table (1) . The results appear that infection in cattle is highly age-dependent ,the young calves showing highest prevalence and intensity of shedding the organism table (1). Out of (95) stool samples examined for children suffering from diarrhea (18) $(18.9 \%)$ samples were positive for Cryptosporidium sp. ,highest prevalence was in the age group of one - three years $(45.4 \%)$ table (2).

This study also revealed the significant association between infection with Cryptosporidium and diarrhea.

In this present study, there are no significant differences between Auramine $\mathrm{O}$ stain and Ziehl Neelsen technique, both are specific for diagnosis of Cryptosporidium in prepared faecal samples

The appearance of detected Cryptosporidium oocysts after staining with modified Ziehl Neelsen as bright red spherical oocysts with a diameter of $5.2 \times 4.4 \mu \mathrm{m}$ figure (1).

Cryptosporidium oocysts appear ring or ovoid shaped and exhibit a characteristically bright apple-green fluorescence against a dark background, measuring 4-5 $\mu \mathrm{m}$ in diameter when stained with Auramine O figure (2). 
Proceeding of the Eleventh Veterinary Scientific Conference, 2012; 280 -285.

Table 1 : Prevalence of Cryptosporidium oocysts in calves in Mosul city

\begin{tabular}{|c|c|c|c|c|c|c|}
\hline Age & \multirow{2}{*}{$\begin{array}{c}\text { Number of } \\
\text { animals } \\
\end{array}$} & \multicolumn{2}{|c|}{ Positive cases } & ZN & AO & $\begin{array}{c}\text { Clinical } \\
\text { signs }\end{array}$ \\
\cline { 3 - 7 } & 1 & N. & $\%$ & & & \\
\hline $1-2$ days & 9 & 5 & 55.5 & + & + & Diarrhea \\
\hline $1-2$ weeks & 18 & 6 & 33.3 & - & - & Diarrhea \\
\hline $\begin{array}{c}2 \text { weeks }-1 \\
\text { month }\end{array}$ & 22 & 11 & 50 & - & - & Diarrhea \\
\hline $1-2$ months & 25 & 10 & 13.3 & - & - & Diarrhea \\
\hline Up to 1 year & 78 & 34 & 43.56 & & & \\
\hline Total & & & & & \\
\hline
\end{tabular}

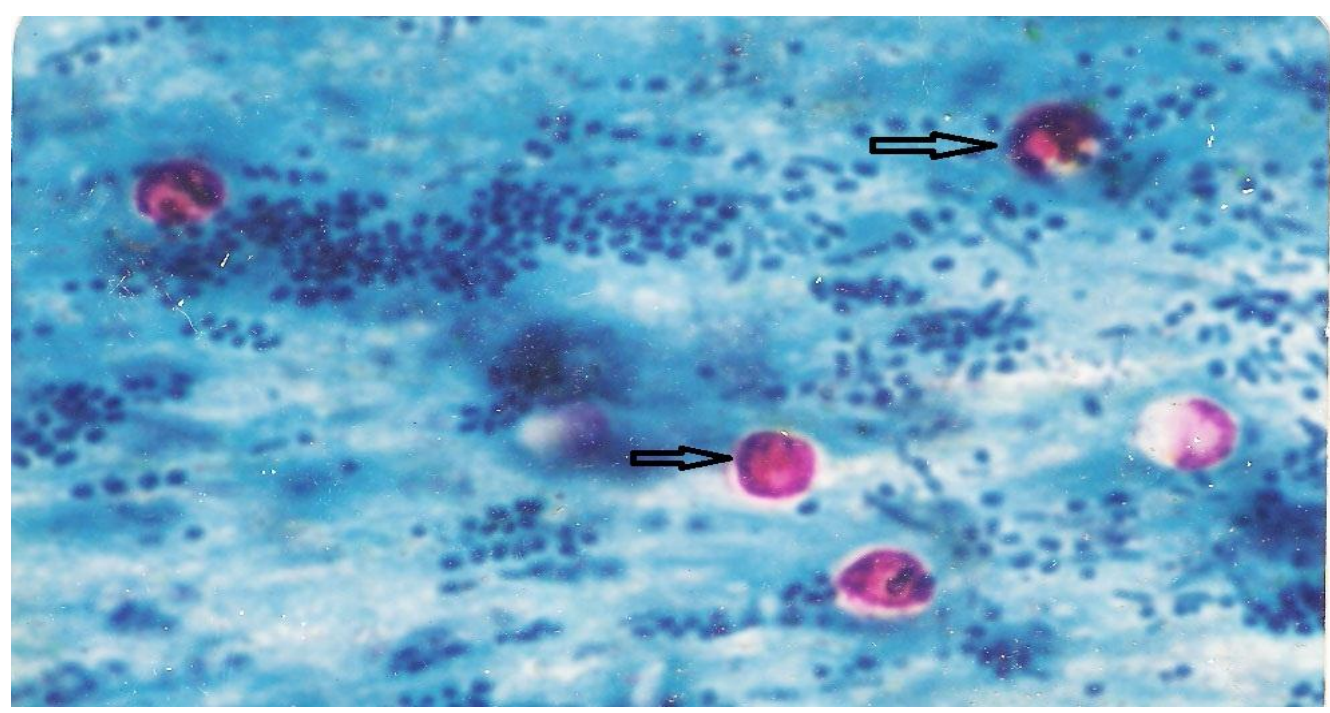
100X

Figure(1): The oocysts of Cryptosporidium sp. Staining with modified Zeihl-Neelsen

Table 2: Prevalence of Cryptosporidium oocysts in children in Mosul city

\begin{tabular}{|c|c|c|c|c|c|c|}
\hline \multirow[t]{2}{*}{ Age } & \multirow{2}{*}{$\begin{array}{l}\text { Number of } \\
\text { children } \\
\text { examined }\end{array}$} & \multicolumn{2}{|c|}{ Positive cases } & \multirow[t]{2}{*}{$\mathrm{ZN}$} & \multirow[t]{2}{*}{$\mathrm{AO}$} & \multirow{2}{*}{$\begin{array}{c}\text { Clinical } \\
\text { signs }\end{array}$} \\
\hline & & N. & $\%$ & & & \\
\hline $1-6$ month & 39 & 4 & 10.2 & + & + & Diarrhea \\
\hline $6-12$ month & 28 & 7 & 25 & + & + & Diarrhea \\
\hline $1-3$ years & 11 & 5 & 45.4 & - & - & Diarrhea \\
\hline $3-6$ & 10 & 1 & 10 & - & - & Diarrhea \\
\hline $6-12$ & 7 & 1 & 14.2 & - & - & Diarrhea \\
\hline Total & 95 & 18 & 18.9 & & & \\
\hline
\end{tabular}


Proceeding of the Eleventh Veterinary Scientific Conference, 2012; 280 -285.

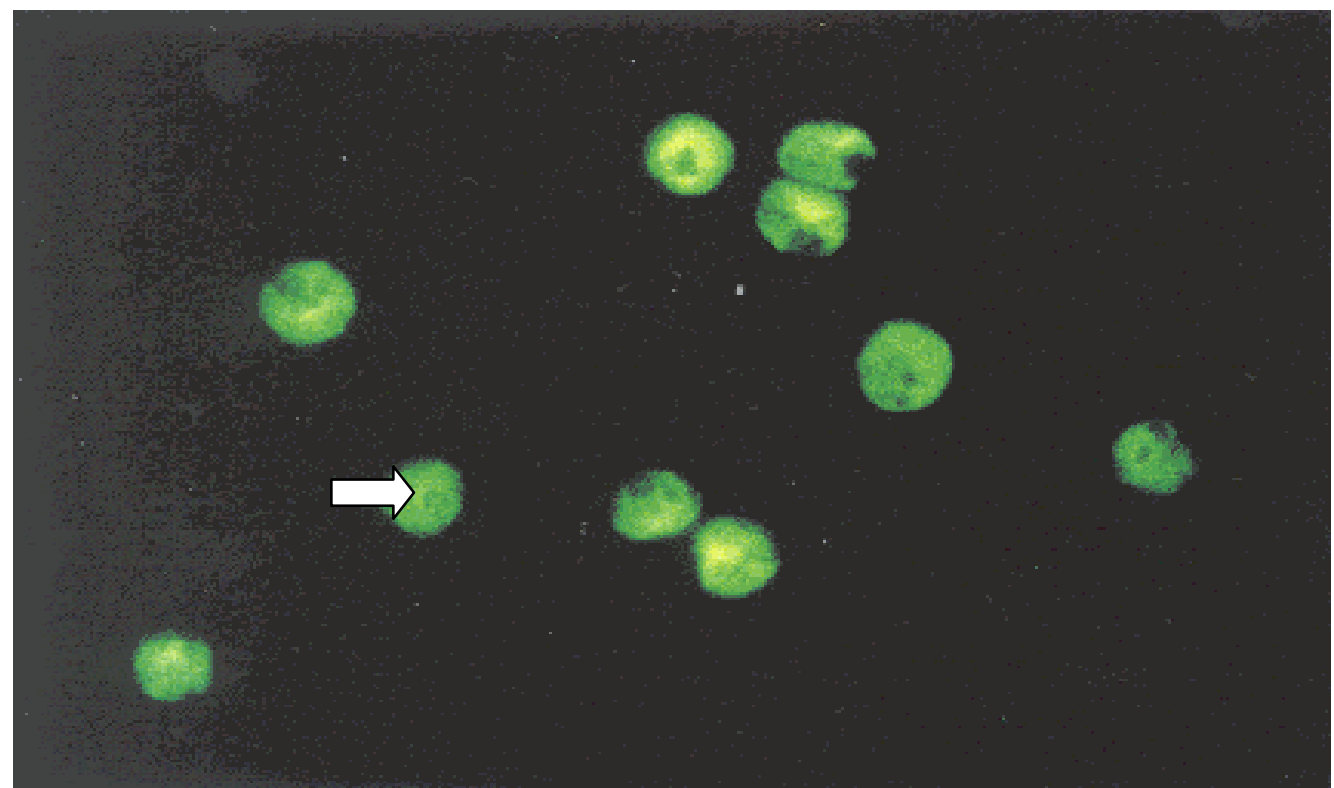

Figure(2): The oocysts of Cryptosporidium sp. Staining with Auramine O by Fluorescent microscope 100X

\section{Discussion}

Cryptosporidium sp. is a common intestinal pathogen of animals and humans. It may have an important economic impact on farms and cause potentially zoonotic infections (17).

In the present study, the overall prevalence of Cryptosporidium in calves was $(43.56 \%)$ .These results agreed with studies carried out in calves in Kars province, Turkey have reported a prevalence of $42.8 \%$. The rate of infection was $30.3 \%$ in calves with diarrhea and $10 \%$ in healthy calves (6). According to another study carried out in young calves in New Zealand, (10) have reported a prevalence of $28 \%$ with PCR. For the first time in Argentina, infection to Cryptosporidium was reported in $17 \%$ of calves with $<30$ days old (7).

Results appear that infection in cattle is highly age-dependent table (1), with young calves showing the highest prevalence and intensity of shedding the organism (18). Therefore, these young animals can shed the oocyst of Cryptosporidium which has a wide host range and is considered to be potentially zoonotic (10).

Out of (95) stool samples examined for children suffering from diarrhea (18) (18.9\%) samples were positive for Cryptosporidium sp. table (2) .Oocysts excretion is often intermittent and occurs in small quantities, thus, prevalence would be undoubtedly higher if more than one stool sample from each child were examined (8).Children with cryptosporidiosis are indistinguishable from non-Cryptosporidium gastroenteritis children with respect to their age, nutritional status, severity of diarrhea or metabolic disturbance (19).

In the developing world, the association of Cryptosporidium with acute and persistent diarrhea in children is striking. Several cross sectional studies in children with diarrhea suggest that cryptosporidiosis is endemic in developing world with prevalence of up to $26 \%$ in Mexican and $16.5 \%$ in Brazilian children with diarrhea (4). Prevalence in African countries, Central and South American countries, Asian countries is greater than in Europe and North America (20). In Pakistan and Indonesia the parasite has been found in 10.3 and $8.2 \%$ of children with diarrhea respectively $(19,21)$.

Highest prevalence was in the age group of one - three years (45.4\%) table (2). Cryptosporidium has been reported in persons from three days to 95 years of age. But data suggest that young children are more susceptible to infection(15). This corresponds to the weaning period when the children are exposed to contaminated environment, food and water. Similar observations were made in Indonesia, Pakistan and Ghana where children less than 2 years old were found to be the most susceptible (19). In contrast, higher age group (4.5 years) as found to be the most susceptible in Kuwait(22). 
The most important risk factor for cryptosporidiosis in children is contact with a person suffering from diarrhea (12). Other possible methods of transmission are association with dogs and cats, consumption of untreated milk, water supply and dummies (15).Thus, the major routes of transmission associated with this parasitosis should be assessed further investigation. The clinical findings and the course of illness do not help in indicating the source of patients' infection. Cryptosporidium lacks host specificity (12) and thus is a potential zoonosis (9). The role of Cryptosporidium in causing disease in infected patients is unclear, but diarrhea has been experimentally induced in lambs and calves (17).

This study also revealed the significant association between infection with Cryptosporidium and diarrhea. There are much data about cryptosporidial human infection in the world especially in children with or without diarrhea. (23) showed that intestinal parasitic infection is a common health problem among children in Saudi Arabia and Cryptosporidium was reported from $8.3 \%$ inpatients and $2.3 \%$ outpatients. (24) revealed that infection with Cryptosporidium species and Entamoeba histolytica were more prevalent in patients with acute diarrhea than in healthy control subjects, for all ages and specifically for those 0-12 months of age in Dhaka, Bangladesh .

In this present study, there are no significant differences between Auramine $\mathrm{O}$ stain and Ziehl Neelsen technique, both are specific for diagnosis of Cryptosporidium in prepared faecal samples and the prevalence rate of cryptosporidiosis was seen to be higher when this stain was used (25).

It was concluded that young calves and children play an important role in maintaining infection in nature and represent an important risk factor for transmission of infection to other humans and animals.

Further studies on characterization and subtyping of human, animal and environmental isolates are required to evaluate the public health significance of $C$. parvum infection in livestock, the exact sources and routes of transmission and population dynamics of Cryptosporidium . Control measures based on such knowledge shall be useful in reducing morbidity and mortality due to cryptosporidiosis in children.

\section{References}

1- Caccio, S. M.(2004) New methods for the diagnosis of Cryptosporidium and Giardia. Parasitology . 46: 151-5.

2- Dubey, J. P. ; .Speer, C. A. and Fayer, R. (1999) . Cryptosporidiosis of Man and Animals. CRC Press. 199 p.

3- Yu, J. R.; Lee, J. K. and Seo, M. (2004). Prevalence of cryptosporidiosis among the villagers and domestic animals in several rural areas of Korea. Korean J. Parasit., 42: 1-6.

4- Nydam, D. V. ; Lindergard, G.and Santucci, F.(2005). Risk of infection with Cryptosporidium parvum and Cryptosporidium hominis in dairy cattle in the New York City watershed. American Journal Veterinary Research . 66:413-7.

5- Youn, H. (2009). Review of zoonotic parasites in medical and veterinary fields in the republic of Korea. Korean Journal of Parasitology 47: 133-141.

6- $\quad$ Sari, B., Akta , M.S. and Arslan, M.O. (2008).The prevalence of Cryptosporidium spp. in calves in Erzurum province. Turkiye Parazitolojii Dergisi 32(2): 116-119 (in Turkish with English abstract).

7- $\quad$ Del Coco, V.F., Cordoba, M.A. and Basualdo, J.A. (2008). Cryptosporidium infection in calves from a rural area of Buenos Aires, Argentina. Veterinary Parasitology 158: 31-35.

8- $\quad$ Abu-Alrub, S.M., Abusada, G.M., Farraj, M.A. and Essawi, T.A. (2008). Prevalence of Cryptosporidium spp. in children with diarrhea in the West Bank, Palestine. The J. Infec. in Developing Countries 2(1): 59-62.

9- $\quad$ Bajer, B. (2008). Cryptosporidium and Giardia spp. infections in human, animals and the environment in Poland. Parasit. Res., 104: 1-17. 


\section{Proceeding of the Eleventh Veterinary Scientific Conference, 2012; 280 -285.}

10- Brook, E., Hart, C.A., French, N. and Christley, R. (2008). Prevalence and risk factors for Cryptosporidium spp. infection in young calves. Veterinary Parasitology 152: 46-52.

11- Hamnes, I.S., Gjerde, B. and Robertson, L. (2006). Prevalence of Giardia and Cryptosporidium in dairy calves in three areas of Norway. Veterinary Parasitology 140: 204216.

12- Tzipori, S. and Ward, H. (2002). Cryptosporidiosis: biology, pathogenesis and disease. Microbes and Infection. 4(10): 1047-1058.

13- Bukhari, Z. \& Smith, H.V. (1995). Effect of three concentration techniques on viability of Cryptosporidium parvum oocysts recovered from bovine feces. Journal of Clinical Microbiology. 33(10): 2592-2595.

14- Casemore, D.P.(1991). Laboratory methods for diagnosing cryptosporidiosis. Journal Clinical Pathology. 44: 445-451.

15- Fayer, R.(2004). Cryptosporidium: A water borne zoonotic parasite. Veterinary Parasitology .126:37-56.

16- Statistical Package for the Social Science Advance Statistic TM Version 11.5 (2002).SPSS Inc, Chicago II.

17- Ranjbar-Bahadori, Sh.; Sangsefidi, H.; Shemshadi, B. and Kashefinejad, M.(2011). Cryptosporidiosis and its potential risk factors in children and calves in Babol, north of Iran. Tropical Biomedicine . 28(1): 125-131.

18- Quilez, J., Sanchez-Acedo, C., Clavel, A. and Causape, A.C. (1996). Prevalence of Cryptosporidium and Giardia infections in cattle in Aragon (northeastern Spain). Veterinary Parasitology 66: 139-146

19- Iqbal, J. ; Munir, M.A. and Khan, M.A.(1999). Cryptosporidium infection in young children with diarrhea in Rawalpindi, Pakistan. American Journal Tropical Medicine Hygiene $.60: 868-70$.

20- Garcia, L.S.; Bruckner, D.A.;Brewer, T.C. and Shimizu, R.Y.(1983). Techniques for the recovery and identification of Cryptosporidiuum oocysts from stool specimens. Journal Clinical Microbiolgy . 18: 185-90.

21- Katsumata,T.; Hosea, D.; Wasito, E.B.; Kohno, S.; Soeparto, P. and Ranuh, I.G.(1998).Cryptosporidiosis in Indonesia: A hospital based study and a community based survey. American Journal Tropical Medicine Hygiene .59:628-32.

22- Sulaiman, I.M. ; Hira, P.R. ; Zhou, I.; Al-Ali, F.M.; Shelahi, F.A.; Shweiki, H.M. and Iqbal, J.(2005). Unique endemicity of Cryptosporidiosis in children in Kuwait. Journal Clinical Microbiolgy .43:2805-9.

23- Al-Braiken, F.A. (2008). Is intestinal parasitic infection still a public health concern among Saudi children. Saudi Medicine Journal 29(11): 1630-1635.

24- Haque, R., Mondal, D., Karim, A., Molla, I.H., Rahim, A., Faruque, A.S., Ahmad, N., Kirkpatrick, B.D., Houpt, E., Snider, C. and Petri, W.A.Jr. (2009). Prospective case-control study of the association between common enteric protozoal parasites and diarrhea in Bangladesh. Clinical Infectious Diseases 48(9):1191-1197.

25- De Quadros, R.M. ; Sandra, M. T. and Camila, R. A.(2006). Detection of Cryptosporidium oocysts by auramine and Ziehl Neelsen staining methods. Parasitogyl Latinoam . 61: $117-120$. 